\title{
sciendo
}

Current Issues in Pharmacy and Medical Sciences

Formerly ANNALES UNIVERSITATIS MARIAE CURIE-SKIODOWSKA, SECTIO DDD, PHARMACIA

\section{Antibacterial and cytotoxic activity of metronidazole and levofloxacin composites with silver nanoparticles}

\author{
Olexandra Ilkov ${ }^{1}$, Nazar Manko ${ }^{2}$, Svitlana Bilous ${ }^{3 *}{ }^{*}$, Gennadiy Didikin $^{4}$, \\ Olga Klyuchivska ${ }^{2}$, Nadiya Dilay ${ }^{5}$, Rostyslav Stoika ${ }^{2}$
}

\author{
${ }^{1}$ Institute of Animal Biology, NAS of Ukraine, Lviv, Ukraine \\ ${ }^{2}$ Institute of Cell Biology, NAS of Ukraine, Lviv, Ukraine \\ ${ }^{3}$ Danylo Halytsky Lviv National Medical University, Lviv, Ukraine \\ ${ }^{4}$ E.O. Paton Electric Welding Institute, NAS of Ukraine, Kyiv, Ukraine \\ ${ }^{5}$ LLC "ed cosmetics", Lviv, Ukraine
}

\section{INFO \\ Received 04 February 2020 Accepted 01 December 2021}

\section{Keywords:}

silver nanoparticles, metronidazole,

levofloxacin,

antibacterial activity, cytotoxic action,

MTT-test.

\begin{abstract}
The aim of the work is to to ascertain their antibacterial activity, as well as the toxic effects toward human cells of composites of silver nanoparticles immobilized by electron-beam technology onto crystals of antimicrobial agents metronidazole and levofloxacin The assessment of antibacterial activity and cytotoxic action of silver naonparticled metronidazole and levofloxacin composites was carried out using the MTT-test. Objects of study of antibacterial activity were three strains of microorganisms: Staphylococcus aureus ATCC25923, Escherichia coli dH5a, Pseudomonas aeruginosa ATCC9027. For the investigation of cytotoxic action, cells of HEK 293 line obtained from human kidney embryos were used. Nanocomposites of metronidazole and levofloxacin were tested at concentrations known as the minimum toxic dose of antibiotics and at concentrations reduced/increased in 2 times.

Immobilization of silver nanoparticles on the surface of metronidazole and levofloxacin by electron-beam technology gives a different effect on their antibacterial and cytotoxic activity. Nanocomposites of metronidazole exhibit a weaker antibacterial effect on E. coli than metronidazole alone, while levofloxacin nanocomposites have higher antibacterial activity compared to levofloxacin alone. Nanocomposites of the levofloxacin, compared to free levofloxacin, are characterized by a higher antibacterial effect towards gramnegative bacteria (E. coli), but practically do not differ in activity toward $P$. aeruginosa and S. aureus. Immobilization of silver nanoparticles on metronidazole crystals does not affect on its cytotoxicity relative to pseudonormal human cells line HEK 293, while the nanocomposites of levofloxacin with silver are more toxic to these cells than levofloxacin alone.
\end{abstract}

\section{INTRODUCTION}

For over a century, silver has been used in clinical practice as an antimicrobial agent due to its effectiveness in neutralizing a wide range of aerobic, anaerobic, grampositive and gram-negative bacteria, as well as fungi and viruses [1]. Silver nanoparticles obtained by diverse methods show significant differences in their structure, shape and size, as well as differences in their physicochemical, technological, pharmacological and toxicological properties. Against the background of optimistic prospects for the use

\footnotetext{
* Corresponding author

e-mail: svitlana.bilous@gmail.com
}

of nanotechnologies and nanomaterials in medicine, there is a lack of objective scientific data about their effectiveness and potentially negative impacts on tissues and human organs.

\section{AIM}

The aim of the work is to investigate the antibacterial activity of synthesized composites of silver nanoparticles immobilized on crystals of antimicrobial agents, as well as their toxic effects toward human cells. 


\section{MATERIALS AND METHODS}

Silver nanocomposites of metronidazole and levofloxacin was created out using the electron beam equipment shown schematically in Figure 1.

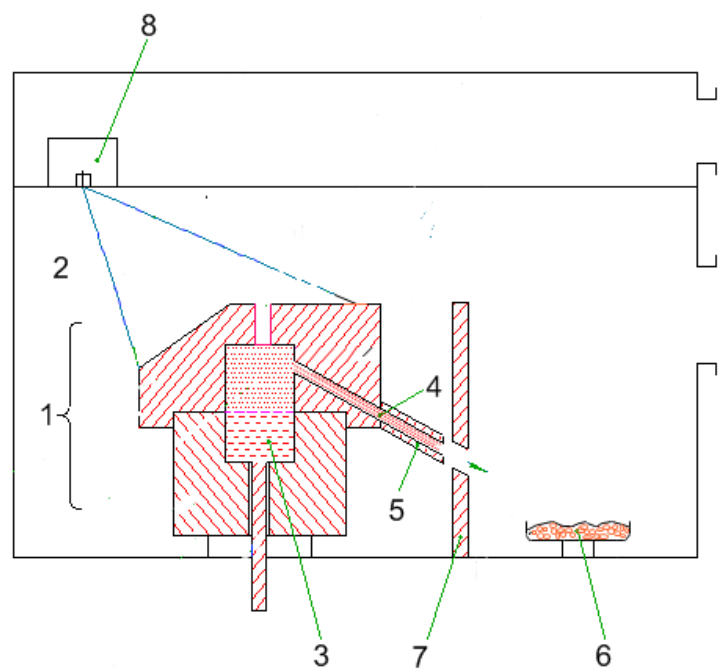

Figure 1. Scheme of electron-beam vacuum evaporation and condensation of silver from a steam flow

The evaporator (1) is located in the technological chamber (2) of the installation. At the bottom, there is a container (3) for forming a liquid bath of evaporative material, as well as an outlet (4). The evaporator holds the nozzle (5) in order to adjust the shape, size and direction of the vapor flow to the location of the cooled container (6) with the carrier material. Additional protection of the material from overheating is provided by a cooling screen (7).

Evaporative material (silver) in the form of a metal ingot with an appropriate size and weight is placed in the evaporator (1). In a copper container (6), the carrier material is mixed with a powder of either metronidazole or levofloxacin in the appropriate quantities.

The technological chamber (2) is sealed, creating a vacuum $10^{-4} \mathrm{~mm} \mathrm{Hg}$ in its volume. The cooling system of the container (6) with the metronidazole or levofloxacin powder and its stirring mechanism is switched on. The electron beam beacon (8) is then supplied with power and its ray heat raises temperature that provides the evaporation of silver at an appropriate rate. Within the evaporator (1), there is a vapor of silver that is projected through a hole (4) and nozzle (5) creating a stream of atomized silver that is directed to the location of the container (6). The silver vapor makes contact with the powder of either metronidazole or levofloxacin that was cooled down to a temperature of $30-60^{\circ} \mathrm{C}$ prior to this process. Condensation of silver subsequently occurs on the surface of the metronidazole or levofloxacin particles. Thus, metronidazole-Ag or levofloxacin-Ag composites are formed. After $20 \mathrm{~min}$, the beacon (8) is disconnected, the mixing of the powder in the container (6) is stopped, the evaporator hole (4) is blocked after the cooling of the installation, and the obtained silver-containing metronidazole or levofloxacin composite is removed.
The coating of the metronidazole and levofloxacin by silver nanoparticles was investigated using a raster electron microscope MIRA3 TEScan (Czech Republic). Silver concentration was determined by the method of atomic emission spectrometry with inductively coupled plasma by employing an Optima 2100 DV device (Perkin Elmer, USA). Silver nanoparticles are spherical which is considered to be the least toxic to biological structures.

Structure of the nanocomposites was investigated using a x-ray crystallography analysis using an automatic powder diffractometer STOE STADI P (MoK $\alpha$-radiation stepping removal method, $2^{\circ} \leq 20 \leq 30$, step scan -0.02 , scanning at one point $-5-10 \mathrm{sec})$. We saw that immobilization of silver nanoparticles on metronidazole or levofloxacin substances using the method of electron-beam technology does not change the diffraction pattern. Thus, the nanoparticles of silver do not change the structure of the starting substances, but they coat the surfaces of the crystals of the corresponding substances [2].

Figure 2 and 3 show the scheme and structure of the studied composites of metronidazole and levofloxacin.

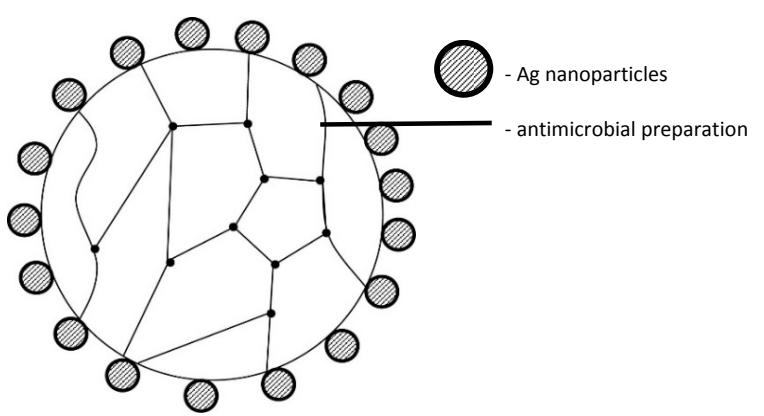

Figure 2. Scheme of the composite structures with metal nanoparticles in the form of discrete coatings on crystals of the organic substances obtained by applying electron-beam technology
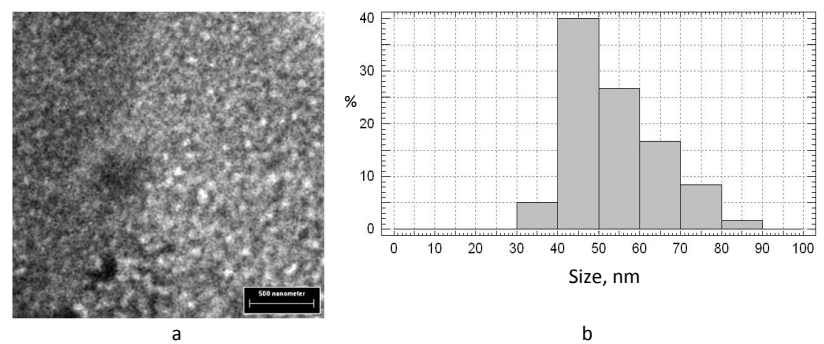

Figure 3. Distribution of silver nanoparticles on the surface of the metronidazole crystals: a) discrete nano-coating structure (×100.000); b) histogram of size distribution of the nanoparticles

A study of the antibacterial and cytotoxic activity of the metronidazole and levofloxacin composites with silver nanoparticles was performed using an MTT-test that is based on the ability of succinate dehydrogenase of the mitochondrial membrane to restore 3-[4,5-dimethylthiazol2-yl]-2,5-diphenyltetrazolium bromide salt (MTT) to the formazan of violet color that accumulates as a result of this reaction in the cytoplasm of the living cells [3]. The intensity of accumulation of formazan in the cytoplasm correlates positively with the level of mitochondrial respiration of cells, and is an important indicator of their viability. The amount of formed formazan in the cell monolayer is proportional 
to the number of viable cells. Dimethylsulfoxide solvent (DMSO), (REALAB, Ukraine) was used to convert insoluble formazan into a colored solution.

Three strains of microorganisms: Staphylococcus aureus ATCC25923, Escherichia coli dH5a, Pseudomonas aeruginosa ATCC9027 were used as objects for studying the antibacterial activity of the nanocomposites. All experiments were conducted with three repeats. The nanocomposites, as well as metronidazole and levofloxacin, were used at a concentration of $10 \mathrm{mg} / \mathrm{ml}$. A suspension of bacteria with OD $=590$ from 0.3 to 0.6 was sown in a tube with a peptone-glucose medium and allowed to rest overnight. The bacterial cultures were then incubated for $4 \mathrm{~h}$ with the studied substances or the nanocomposites. The MTT dye (Sigma-Aldrich, USA) was added in a quantity of $10 \mu \mathrm{l}$ in each test tube and incubated for $1 \mathrm{~h}$ at $37^{\circ} \mathrm{C}$. After incubation, the samples were centrifuged at a rate 3,000 rpm for $10 \mathrm{~min}$. The supernatant liquid was subsequently collected and $1 \mathrm{ml}$ of dimethyl sulfoxide was added per sample and incubated for $1 \mathrm{~h}$ at $37^{\circ} \mathrm{C}$. The amount of the violet formazan after its dissolution in the DMSO was determined at a wavelength $570 \mathrm{~nm}$, using a UV102 spectrophotometer.

For a study of the cytotoxic action of the nanocomposites, cells of HEK 293 line obtained from human kidney embryos were used. The nanocomposites of the metronidazole and levofloxacin were applied at concentrations known as the minimum toxic dose of antibiotics and at concentrations reduced/increased twice [4]. HEK 293 cells were seeded on 96 -well plates $(5.000$ cells/well, $100 \mu \mathrm{l})$. After this, the cells were incubated for $48 \mathrm{~h}$ with the nanocomposites or metronidazole or levofloxacin. Crystals of insoluble formazan were dissolved in the DMSO, and the amount of purple formazan was determined at wavelength $620 \mathrm{~nm}$ using a Reader BioTek ELx800 spectrophotometer (BioTek Instruments, Inc., Winooski, VT, USA. Computer processing of the results was performed on the Excel program that is included in the set of programs "Office 2018" (Microsoft, USA).

\section{RESULTS AND DISCUSSION}

In creating composites with nanoparticles of metals, silver is preferred because of low probability of resistance of the microorganism to silver. In our experiments, metronidazole and levofloxacin in powder forms were employed as carriers for nanocomposite preparation. For the application of silver to the carrier particles, a method providing the dosed amount of silver of a given dispersion was utilized. This is electronbeam vacuum evaporation. By means of its application, condensation of silver from a steam flow forms in space and is directed to the carrier material that is cooled to a temperature lower than its melting point. Mixing of the carrier ensures a uniform distribution of silver nanoparticles on the surface of the antimicrobial preparations. This physical method makes it possible to obtain nanocomposites without impurities [5].
The method of electron-beam technology allows obtaining composites not only with different concentrations of the nanoparticles, but also compositions that are additionally saturated with oxygen. To study the influence of oxygen on the properties of nanocomposites, we investigated metronidazole with silver nanoparticles saturated with oxygen.

In recent years, numerous experimental works and reviews have confirmed the antimicrobial action of silver nanoparticles [1,6-13] and provided information about the characteristics influencing their effectiveness [11]. It is known that silver nanoparticles preferentially enhance the action of antibiotics and antifungal agents. For example, in [12], silver nanoparticles show synergy in a combination with the polymyxin B to a gram-negative bacteria, and in [12] and [13], it does so in a combination with gentamicin, streptomycin, kanamitsin and sulfanilamides. In both experiments, the silver nanoparticles enhanced the antimicrobial effect $[12,13]$. Regarding antagonism in the action of silver nanoparticles and antibiotics, such results were obtained only in their combined action with chloramphenicol [13].

The results of our study on the antibacterial activity of the metronidazole and levofloxacin and their composites with silver nanoparticles (Table 1) obtained by applying electronbeam nanotechnology toward 3 types of microorganisms: S. aureus, E. coli, P. aeruginosa are shown in Figure 4.

Table 1. Studied nanomaterials

\begin{tabular}{|c|c|}
\hline Batch & Characteristics \\
\hline M5 & Metronidazole \\
\hline M6 & Metronidazole- $\mathrm{Ag}\left(\mathrm{C}_{\mathrm{Ag}} 0.0034 \%\right)$ \\
\hline $\mathrm{M} 7$ & Metronidazole-Ag with oxygen $\left(\mathrm{C}_{\mathrm{Ag}} 0,0034 \%\right)$ \\
\hline $\mathrm{M} 8$ & Metronidazole- $\mathrm{Ag}\left(\mathrm{C}_{\mathrm{Ag}} 0.0178 \%\right)$ \\
\hline L9 & Levofloxacin \\
\hline L10 & Levofloxacin- $\mathrm{Ag}\left(\mathrm{C}_{\mathrm{Ag}} 0.00119 \%\right)$ \\
\hline L11 & Levofloxacin- $\mathrm{Ag}\left(\mathrm{C}_{\mathrm{Ag}} 0.00476 \%\right)$ \\
\hline
\end{tabular}

The metranidazole and its composites with silver nanoparticles demonstrated higher activity when $P$. aeruginosa were exposed (reduced viability to $\sim 70 \%$ of $100 \%$ in the control). When $S$. aureus was exposed, the viability index was reduced to $\sim 80 \%$ at $100 \%$ in the control. The metronidazole composite with silver nanoparticles (M8) was more active in E. coli, demonstrating $25 \%$ reduction compared to metronidazole's (M5) action. Such effect was probably due to an increase in the dose of silver, since the metronidazole composites with less concentration of silver nanoparticles (M6, M7) showed a decrease in the activity

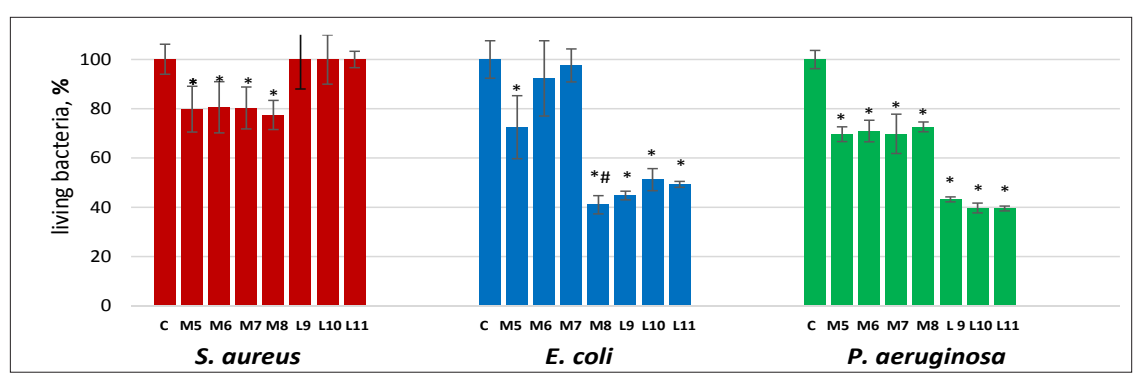

Measured via MTT test,\% - number of live cells vs dose of test substances at $200 \mu \mathrm{g} / \mathrm{ml}$, * - reliably relative to a control (C), \# - reliably relative to metronidazole (M5)

Figure 4. Alive bacterial cells 


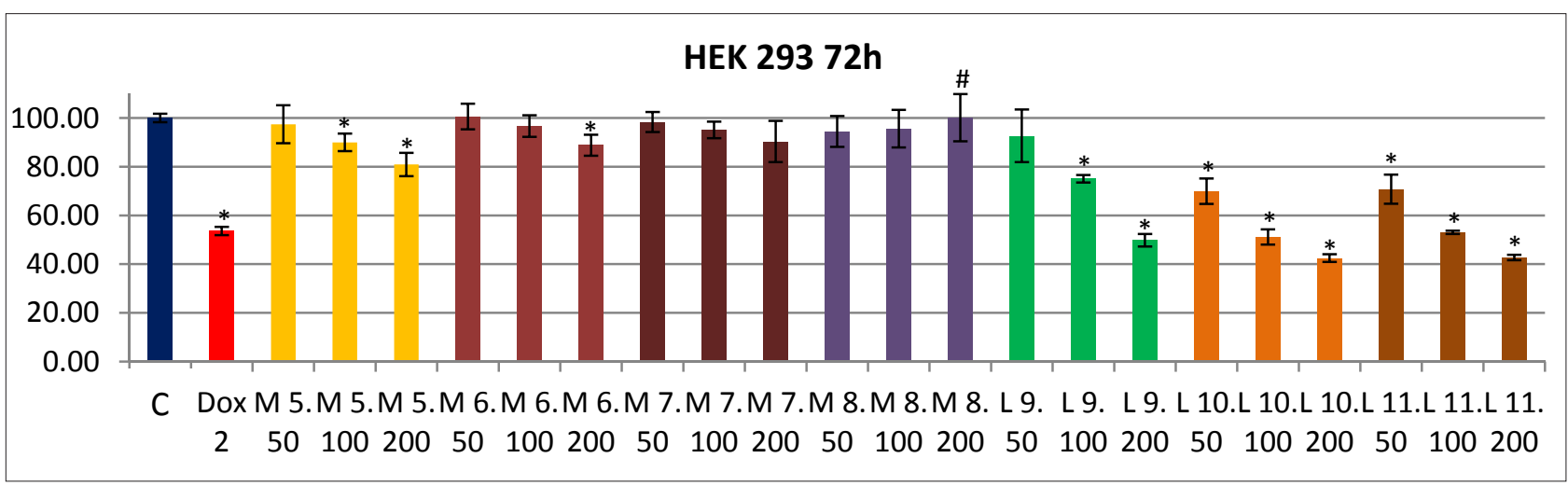

Measured via MTT test, \% - number of live cells vs the dose of test substances in $\mu \mathrm{g} / \mathrm{ml}$, * - reliably relative to the control (C), \# - reliably relative to metronidazole $200 \mu \mathrm{g}$ (M5)

Figure 5. Nacomposite toxicity to live cells of the HEK293 line

toward E. coli, compared to metronidazole's activity. In this case, there was no difference between the activity of the metronidazole composites with silver nanoparticles with oxygen and without it (M6, M7).

The levofloxacin and its composites with silver nanoparticle (L9, L10, L11) demonstrated no activity toward $S$. aureus, however, they caused a $50-60 \%$ reduction in the number of viable $E$. coli and $P$. aeruginosa bacteria.

The results of studying the nanocomposite toxicity toward cells of HEK 293 line are presented in Figure 5. Doxorubicin at a dose of $2 \mu \mathrm{g} / \mathrm{ml}$ was administered as a positive control and showed significant cytotoxic effect.

The metronidazole possessed less cytotoxicity than the doxorubicin, and its nanocomposites practically did not demonstrate toxic action toward HEK 293 cells. Such effect is important when metronidazole composites with silver nanoparticles are applied as antibacterials, since administration will not be accompanied by toxic side effects toward mammalian cells and tissues. In contrast, we observed high cytotoxic action with regard to the action of levofloxacin and its silver nanocomposites (Fig. 5).

Thus, one can assume that immobilization of silver nanoparticles on the surface of the antimicrobial preparations in a powder form allows to expand the therapeutic window of these preparations by combining their action with the antimicrobial action of silver - for which resistance of the bacterial cells was not described. Different cytotoxic effects of the developed antimicrobial composites with silver nanoparticles toward the mammalian cells have been found. The metronidazole and silver nanocomposites do not significantly affect the viability of HEK293 cells, whereas the survival of the mammalian cells under the influence of the levofloxacin nanocomposites was reduced, regardless of silver content in that composite.

\section{CONCLUSIONS}

1. The immobilization of silver nanoparticles on the surface of crystals of the antimicrobial preparations, metronidazole and levofloxacin, was carried out by means of applying electron-beam technology. Our work shows that such modification differentially enhanced the antibacterial activity and cytotoxic action toward the mammalian cells of the applied antimicrobial preparations.
2. The nanocomposites of the metronidazole (M8) demonstrate the most promising result for this technology of obtaining nanoparticles. These show perspective antibacterial activity against gram-negative strains, and did not show significant toxic effects to pseudonormal cells.

3. The nanocomposites of the levofloxacin, compared to free levofloxacin, are characterized by a higher antibacterial effect towards gram-negative bacteria (E. coli), but practically do not differ in activity toward $P$. aeruginosa and $S$. aureus.

4. The immobilization of silver nanoparticles on the metronidazole crystals does not influence its toxicity with regard to pseudonormal human cells of HEK293 line, while the nanocomposites of levofloxacin with silver are more toxic for these cells than free forms of levofloxacin.

\section{ORCID iDs}

Svitlana Bilous (1Dhttps://orcid.org/0000-0002-0746-7696

\section{REFERNCES}

1. Chopra I. The increasing use of silver-based products as antimicrobial agents: useful development or a cause for concern? J Antimicrob Chem. 2007;59:587-90.

2. Bilous S, Dmytriv G, Didikin G, Hudz N, Lesyk R, Kalynyuk T. Study of methal-organic nanomaterials structure by X-ray crystallography analysis as the basis for the development of quality control methods. J Pharm Pharmacol. 2015;3(12):562-8.

3. Trakhtenberg IM, Ulberg ZR, Chekman IS, Dmytrukha NM. Metodychni rekomendatsii Otsinka bezpeky likarskykh nanopreparativ. Kyiv; 2013:108.

4. Morones-Ramirez JR, Winkler JA, Spina CS, Collins JJ. Silver enhances antibiotic activity against gram-negative bacteria. Sci Transl Med. 2013;5(190):190.

5. Movchan BA. Discrete nanosized metallic coatings produced by EB-PVD. Surf Eng. 2016;32(4):258-66.

6. Panáček A, Kvítek L, Smékalová $M$, Večeřová $R$, Kolář $M$, Röderová $\mathrm{M}$, et al. Bacterial resistance to silver nanoparticles and how to overcome it. Nat Nanotechnol. 2018;13:65-71.

7. Burdușel AC, Gherasim O, Grumezescu AM, Mogoanta L, Ficai A, Andronescu E. Biomedical applications of silver nanoparticles: An up-to-date overview Nanomaterials. 2018;8(9):681.

8. Choi Y, Kim H-A, Kim K-W, Lee B-T. Comparative toxicity of silver nanoparticles and silver ions to Escherichia coli. J Environ Sci. 2018;6:50-60.

9. Díez-Pascual A-M. Antibacterial activity of nanomaterials. Nanomaterials. 2018;8:359. 
10. Some S, Sen JK, Mandal A, Asla T, Ustun Y, Yilmaz ES, et al. Biosynthesis of Silver Nanoparticles and Their Versatile Antimicrobial Properties. Mater Res Express. 2018;6(1).

11. Ruden S, Hilpert K, Berditsch M, Wadhwani P, Ulrich AS. Synergistic interaction between silver nanoparticles and membranepermeabilizing antimicrobial peptides. Antibiotic Agents Chemotherapy. 2009;53(8):3538-40.
12. Jain J, Arora S, Rajwade J, Onroy P, Khandelwal S, Paknikar KM. Silver nanoparticles in therapeutics: development of an antimicrobial gel formulation for topical use. Mol Pharm. 2009;6 (5):1388-401.

13. Raheman F, Deshmukh S, Ingle A, Gade A, Rai M. Silver nanoparticles: novel antimicrobial agent synthesized from an endophytic fungus pestalotia sp. isolated from leaves of Syzygium cumini (L). Nano Biomed Eng. 2011;3(3):174-8. 